\title{
BioMedicine
}

\section{MicroRNA-26a-5p as a potential predictive factor for determining the effectiveness of trastuzumab therapy in HER-2 positive breast cancer patients}

Follow this and additional works at: https://www.biomedicinej.com/biomedicine

Part of the Diagnosis Commons, Life Sciences Commons, Medical Sciences Commons, and the Neoplasms Commons

(c) (i)

This work is licensed under a Creative Commons Attribution 4.0 License.

\section{Recommended Citation}

Samavarchi Tehrani, Sadra; Zaboli, Ehsan; Sadeghi, Farzin; Khafri, Soraya; Karimian, Ansar; Rafie, Mahnoosh; and Parsian, Hadi (2021) "MicroRNA-26a-5p as a potential predictive factor for determining the effectiveness of trastuzumab therapy in HER-2 positive breast cancer patients," BioMedicine: Vol. 11 : Iss. 2 , Article 6.

DOI: $10.37796 / 2211-8039.1150$

This Original Articles is brought to you for free and open access by BioMedicine. It has been accepted for inclusion in BioMedicine by an authorized editor of BioMedicine. 


\section{MicroRNA-26a-5p as a potential predictive factor for determining the effectiveness of trastuzumab therapy in HER-2 positive breast cancer patients}

\section{Cover Page Footnote}

We would like to thank Dr. Mahmood Maniati for proofreading and language editing of the earlier drafts of this manuscript, and Dr. Ghasem Janbabaei for assistance in this study. 


\title{
MicroRNA-26a-5p as a potential predictive factor for determining the effectiveness of trastuzumab therapy in HER-2 positive breast cancer patients
}

\author{
Sadra Samavarchi Tehrani ${ }^{\text {a,b }}$, Ehsan Zaboli ${ }^{c}$, Farzin Sadeghi ${ }^{b}$, Soraya Khafri ${ }^{\text {, }}$ \\ Ansar Karimian ${ }^{\mathrm{a}, \mathrm{b}}$, Mahnoosh Rafie ${ }^{\mathrm{a}, \mathrm{b}}$, Hadi Parsian ${ }^{\mathrm{b}, *}$ \\ ${ }^{\text {a }}$ Student Research Committee, Babol University of Medical Sciences, Babol, Iran \\ ${ }^{\mathrm{b}}$ Cellular and Molecular Biology Research Center, Health Research Institute, Babol University of Medical Sciences, Babol, Iran \\ ${ }^{\mathrm{c}}$ Gastrointestinal Cancer Research Center, Mazandaran University of Medical Sciences, Sari, Iran \\ ${ }^{\mathrm{d}}$ Department of Epidemiology, Babol University of Medical Sciences, Babol, Iran
}

\section{Abstract}

Background: Breast cancer $(\mathrm{BC})$ is known as the most prevalent type of cancer among women. Trastuzumab, as an anticancer drug, has been used broadly in human epidermal growth factor receptor 2 (HER-2) positive (+) BC patients. Moreover, accumulating evidence has demonstrated that microRNAs is involved in the pathogenesis BC. Hence, we aimed to investigate the effect of trastuzumab on the expression levels of microRNA-26a in HER-2 positive BC patients.

Methods: This study was conducted among HER-2 + and HER-2 Negative $(-)$ BC patients. Serum expression of microRNA-26a was detected by real-time PCR. Then, we assessed the correlations of microRNA-26a levels with multiple clinico-pathological characteristics of BC.

Results: In HER-2 + patients, the microRNA-26a expression significantly increased after treatment with Docetaxel/ Trastuzumab in comparison to before the treatment levels (p.value $=0.01$ ). However, this overexpression in HER-2 patients after treatment with Docetaxel was not significant compared to the levels before the treatment (p.value $=0.14)$. In addition, the expression of microRNA -26 a has significantly increased in HER-2 + patients who were $\leq 48$ years old and premenopausal after the treatment with Docetaxel/Trastuzumab when compared to the levels before the treatment (p.value $=0.039$ vs. 0.031 , respectively). Furthermore, there was a significant correlation between the expression of microRNA -26a and the tumor size, stage, estrogen receptor (ER) and progesterone receptor (PR) status in the HER-2 + group before and after the treatment (p.value $=0.043,0.042,0.049$ and 0.034 respectively).

Conclusions: Trastuzumab led to overexpression of microRNA-26a in HER-2 + BC patients. It seems that the detecting microRNA -26a expression levels, during or after the trastuzumab therapy could be a useful biomarker for monitoring the therapeutic response in HER-2 + BC patients. However, further studies on large populations of women with HER$2+$ BC are needed to explore this possible novel biomarker, in more detail, within various clinical contexts.

Keywords: Trastuzumab, Real-time PCR, MicroRNA-26a, HER-2 positive, Breast cancer

\section{Introduction}

B reast cancer $(\mathrm{BC})$ is regarded as the most prevalent form of cancer among women in both developed and developing countries, with a high mortality rate worldwide [1]. It was found that approximately $20 \%$ of invasive BC cases amplify human epidermal growth factor receptor 2 (HER-2/NEU/c-ERBB2) [2]. HER-2 receptor is a member of the epidermal growth factor receptor (EGFR) family, and its overexpression is associated with proliferation, metastasis, and poor patient's prognosis [3]. In clinical settings, HER-2+ BC patients are treated with trastuzumab, which is an anti- HER-2 humanized monoclonal antibody $[4,5]$. Emerging evidence has demonstrated that trastuzumab mediates its therapeutic effects mainly through two mechanisms: I) induction of

Received 28 September 2020; revised 21 October 2020; accepted 25 October 2020.

Available online 1 June 2021

* Corresponding author at: Cellular and Molecular Biology Research Center, Health Research Institute, Babol University of Medical Sciences, Babol, Iran, Ganjafrooz Ave, Babol, Iran.

E-mail addresses: hadiparsian@yahoo.com, hadiparsian@mubabol.ac.ir (H. Parsian). 
antibody-dependent cell-mediated cytotoxicity (ADCC), and II) blockage of HER-2 homo- or hetero-dimerization and downstream signaling pathways such as phosphatidylinositol 3-kinase (PI3K)/AKT/mTOR and RAS/RAF/MEK/MAP kinase (MAPK) [6,7]. Despite the reasonable efficacy rate of this drug, the response rate to trastuzumab monotherapy is approximately $30 \%$, and about $60 \%$ for regimens combining trastuzumab with other chemotherapy drugs $[8,9]$. In addition, most patients develop acquired resistance to this drug within one year [10], and unfortunately there are no specific biomarkers for determining the response rate and potential development of acquired resistance to this drug.

MicroRNAs (miRNAs) which are considered to be key members of non-codingRNAs family, are short and single-stranded RNA molecules with a size of 18-24 nucleotide, which play different roles in various cellular events by binding $3^{\prime}$-UTR of target mRNA for the suppression of translation [11-13]. It was found that miRNAs can be measured in different biological body fluids including serum, plasma, and urine [14], and are not only resistant to nucleolytic degradations, but also stable against harsh conditions [15]. Hence, miRNAs can be used as a novel diagnostic and prognostic biomarkers for various diseases, and are able to serve as predictive biomarkers for treatment of neurodegenerative diseases [16], leukemia [17], and various types of cancers, particularly BC [18]. Moreover, changes in the expression miRNAs levels in cancer cells have been related with prognosis and response to target therapies such as trastuzumab [19,20]. In addition, an increased expression level of miRNA-194 as well as blocked cell migration has been demonstrated in BC cell lines of those treated with trastuzumab, which shows the effect of tratuzumab on miRNA194 expression, and its anti-tumor activity on HER2overexpressing BC cell lines [21]. Interestingly, miRNA-26a, as a tumor suppressor miRNA, is downregulated in BC cell lines. In addition, its upregulation induces apoptosis by metadherin (MTDH), enhancer of zeste homolog 2 (EZH2) and myeloid cell leukemia 1 (MCL-1) [22,23]. Besides, in BC cell lines, trastuzumab affects the expression miRNA-26a and miRNA-30b levels, and these miRNAs play a vital role in trastuzumab therapy by targeting cyclin E2 [24].

There are only few studies in the literature about the critical role of miRNAs and their dysregulation in target monotherapy with trastuzumab in biological fluids such as serum, plasma, and urine in BC patients. Moreover, to the best of our knowledge, no valid non-invasive biomarkers have ever been found for determining the response to targeted monotherapy with trastuzumab. Therefore, we assessed the effects of trastuzumab on the serum miRNA-26a expression levels in HER-2+ BC patients with the aim of introducing a reliable, innovative biomarker candidate, to be used in the clinical settings.

\section{Materials and methods}

\subsection{Study design and sample collection}

The present study was conducted among 45 patients with BC, who had been recruited from March 2018 to March 2019, to the Imam Khomeini Hospital in Mazandaran, Iran (this is the main oncology center for admissions of BC patients in Mazandaran). BC diagnosis was confirmed, based on clinical examination and histopathology tests performed by an expert pathologist. The study protocol was reviewed and approved by the local Ethical Committee at our institution (1396.65), and a written Informed Consent was obtained from all the patients.

Inclusion criteria were as follows: BC patients with immunohistochemical (ISH) staining for HER-2 protein of $3+$ intensity, or amplification of the HER2 gene on fluorescence in situ hybridization (FISH), and no pervious therapy with trastuzumab. Exclusion criteria were prior history of cardiovascular disease (CVD), chronic kidney disease (CKD), diabetes mellitus (DM), rheumatoid arthritis (RA), and any type of cancer.

All the patients underwent a histological examination and a blood sample was collected from each of them. The participants were classified as HER-2+ $B C$ or HER-2- BC, and were subsequently divided into two subgroups: I) HER-2 positive $(+)$ BC (the study group - treated with Trastuzumab), including 24 patients, and II) HER-2 negative (-) BC (the control group - not treated with Trastuzumab), including 21 patients.

All HER-2+ BC patients received 4 cycles of triweekly doxorubicin (Adriamycin, $60 \mathrm{mg} / \mathrm{m} 2$ ) and Cyclophosphamide $(600 \mathrm{mg} / \mathrm{m} 2)$, followed by $4 \mathrm{cy}-$ cles of tri-weekly Docetaxel (taxotere, $75 \mathrm{mg} / \mathrm{m} 2$ ) plus Trastuzumab (Herceptin, $6 \mathrm{mg} / \mathrm{m} 2$ ). Each patient in the HER-2 - group (control) received 4 cycles of tri-weekly doxorubicin $(60 \mathrm{mg} / \mathrm{m} 2)$ and Cyclophosphamide $(600 \mathrm{mg} / \mathrm{m} 2)$ (similarly to the HER-2 + BC group). However, after receiving these two drugs, they received Docetaxel $(75100 \mathrm{mg} / \mathrm{m} 2)$ only (without Trastuzumab), according to The 
National Comprehensive Cancer Network NCCN guidelines (http://www.nccn.org/). $5 \mathrm{~mL}$ blood sample was taken from each participant after signing the Informed Consent.

In the HER-2+ BC group, blood samples from 24 patients were obtained before administering Docetaxel $(75 \mathrm{mg} / \mathrm{m} 2)$ plus Trastuzumab $(6 \mathrm{mg} / \mathrm{m} 2)$ (at the beginning of the 5 th course). The subsequent (follow-up) blood samples from these 24 patients were obtained after the administration of these two drugs (at the beginning of the 9th course).

In the HER-2- BC group, blood samples from 21 patients were obtained before administering Docetaxel $(75 \mathrm{mg} / \mathrm{m} 2)$ (at the beginning of the 5 th course). The subsequent (follow-up) blood samples from these 21 patients were obtained after the administration of this drug (at the beginning of the 9th course) (Fig. 1).

Blood sampling

$5 \mathrm{~mL}$ blood sample was taken from each participant. All of Blood samples were centrifuged at $2500 \mathrm{~g}$ for 10 minutes at $4^{\circ} \mathrm{C}$. Furthermore, serum samples were transferred to $2 \mathrm{~mL}$ microtubes and centrifuged for a second time at $12,000 \mathrm{~g}$ for 10 minutes at $4^{\circ} \mathrm{C}$. The serum samples were transferred at $-80^{\circ} \mathrm{C}$ until final analysis.

\subsection{Isolation of $R N A$}

Total RNA was extracted from the serum of patients by RiboEX LS (GeneAll, Seoul). $600 \mu \mathrm{L}$ RiboEX LS Reagent was added to $200 \mu \mathrm{L}$ serum, and was incubated for 5 minutes at room temperature $\left(25^{\circ} \mathrm{C}\right)$, then, $160 \mu \mathrm{L}$ of chloroform was added and vigorously shaken, and the samples were centrifuged at $12000 \mathrm{~g}$ for 15 minutes at $4^{\circ} \mathrm{C}$. Furthermore, supernatants were mixed with $400 \mu \mathrm{L}$ of isopropanol and incubated overnight at $-20^{\circ} \mathrm{C}$. After centrifuging at $12000 \mathrm{~g}$ for 1 hour at $4^{\circ} \mathrm{C}$, the resulting pellets were washed with $75 \%$ ethanol and centrifuged at $7500 \mathrm{~g}$ for 5 minutes at $4^{\circ} \mathrm{C}$. After allowing the ethanol to completely remove, the pellets were dissolved in $25 \mu \mathrm{L}$ of diethylenepyrocarbonatetreated water (DEPC-treated water) (SinaClon. Iran). The quality/quantity and purity of RNA was analyzed by optical density measurement with NanoDrop.

\subsection{Synthesis of specific $c D N A$}

Synthesis of complementary DNA (cDNA) was done by specific stem-loop primers for microR-26a$5 p$ and microRNA-16. In brief, cDNA synthesis was conducted in a $10 \mu \mathrm{l}$ reaction mixture: $160 \mathrm{ng}$ of total
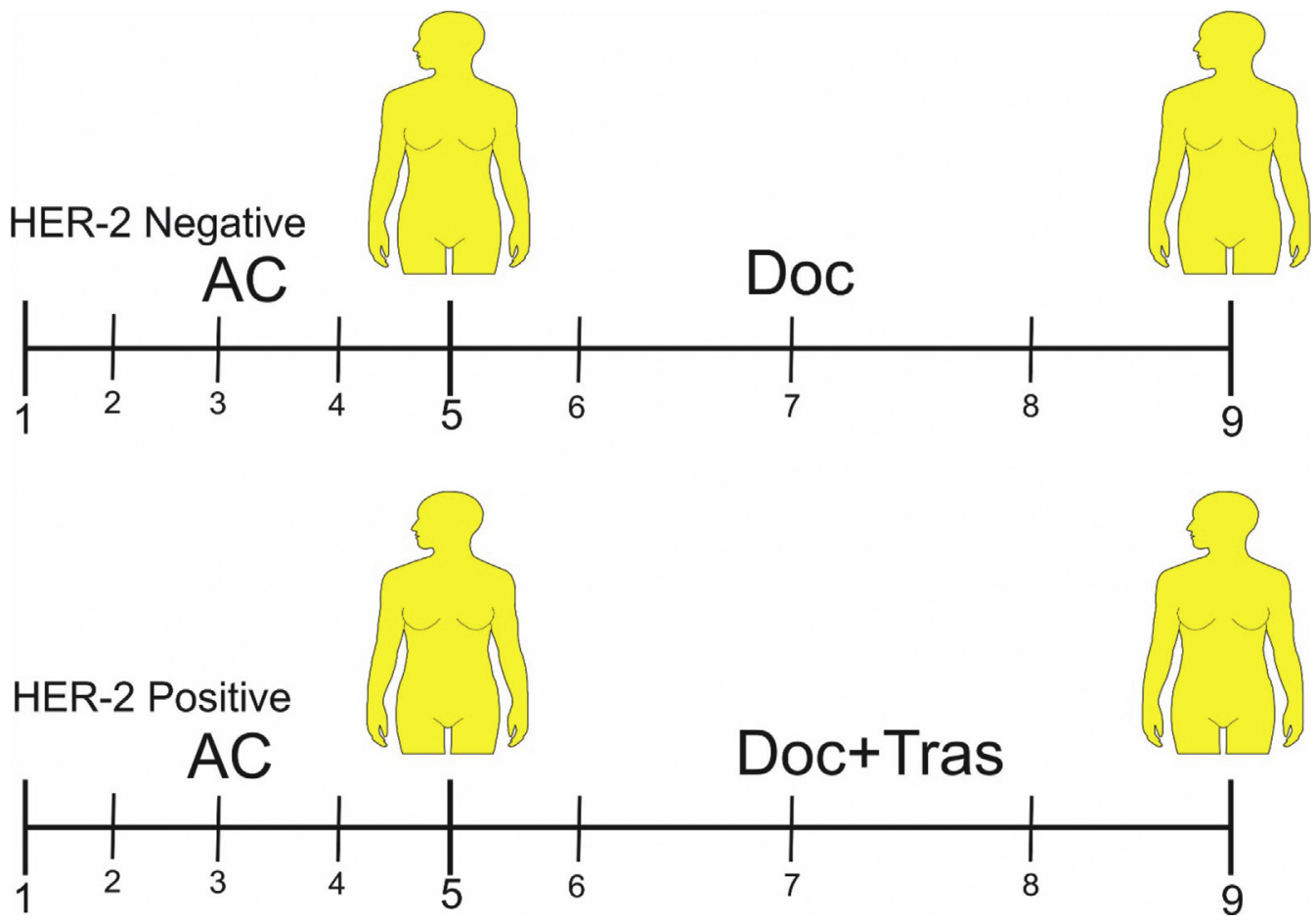

Fig 1. Blood sampling model. Abbreviation: AC (Adriamycin $=60 \mathrm{mg} / \mathrm{m}^{2}$ and Cyclophosphamide $=600 \mathrm{mg} / \mathrm{m}^{2}$, DOC $\left(\right.$ Docetaxel $\left.=75 \mathrm{mg} / \mathrm{m}^{2}\right)$, Tras (Trastuzumab $\left.=6 \mathrm{mg} / \mathrm{m}^{2}\right)$. 
Table 1. The primer sequences for cDNA synthesis and quantitative real-time PCR ( $q R T-P C R)$.

\begin{tabular}{lll}
\hline miRBase accession no. & Primer name & Sequence $\left(5^{\prime} 3^{\prime}\right)$ \\
\hline MIMAT0000082 & has-miR-26a-5p-RT ${ }^{1}$ & GTCGTATCCAGTGCAGGGTCCGAGG \\
& TATTCGCACTGGATACGACAGCCT & CGCCGCTTCAAGTAATCCAGG \\
MIMAT0000069 & has-miR-26a-5p-Forward & GTCGTATCCAGTGCAGGGTCCGAG \\
& & GTATTCGCACTGGATACGACCGCCA \\
& AT & AT \\
& has-miR-16-5p- Forward & GGTAGCAGCACGTAAATATTGGCG \\
& Universal- reverse (UR) & GTGCAGGGTCCGAGGT \\
\hline
\end{tabular}

${ }^{1}$ Stem-loop primer for cDNA synthesis

Table 2. Characteristics of included HER-2 negative and positive breast cancer patients.

\begin{tabular}{|c|c|c|c|}
\hline Variable & & $\begin{array}{l}\text { HER-2 Negative breast cancer } \\
\text { N }(\%)\end{array}$ & $\begin{array}{l}\text { HER-2 positive breast cancer } \\
\mathrm{N}(\%)\end{array}$ \\
\hline Age $($ Mean $\pm S D)$ & & $(51.1 \pm 11.2)$ & $(49.9 \pm 10.1)$ \\
\hline \multirow[t]{2}{*}{ ER status } & Positive & $15(71.4)$ & $15(62.5)$ \\
\hline & Negative & $6(28.6)$ & $9(37.5)$ \\
\hline \multirow[t]{2}{*}{ PR status } & Positive & $15(71.4)$ & $12(50.0)$ \\
\hline & Negative & $6(28.6)$ & $12(50.0)$ \\
\hline \multirow[t]{3}{*}{ Tumor size } & pT1 & $6(28.6)$ & $5(20.8)$ \\
\hline & pT2 & $13(61.9)$ & $14(58.3)$ \\
\hline & pT3 & $2(9.5)$ & $5(20.8)$ \\
\hline \multirow{4}{*}{ Lymph nodes } & No & $9(42.9)$ & $12(50.0)$ \\
\hline & N1 & $7(33.3)$ & $8(33.3)$ \\
\hline & $\mathrm{N} 2$ & $3(14.3)$ & $4(16.7)$ \\
\hline & N3 & $2(9.5)$ & $0(0.0)$ \\
\hline \multirow[t]{3}{*}{ Tumor stage } & I & $2(9.5)$ & $7(29.2)$ \\
\hline & II & $12(57.1)$ & $12(50.0)$ \\
\hline & III & 7 (33.3) & $5(20.8)$ \\
\hline \multirow[t]{3}{*}{ Tumor grade } & I & 1)4.8) & $3(12.5)$ \\
\hline & II & $16(76.2)$ & $18(75.0)$ \\
\hline & III & $4(19.2)$ & $3(12.5)$ \\
\hline \multirow{2}{*}{ Histological subtype } & IDC & $17(81.0)$ & $24(100.0)$ \\
\hline & ILC & $4(19.0)$ & $0(0.0)$ \\
\hline \multirow[t]{2}{*}{ Menopausal status } & Premenopausal & $11(52.4)$ & $16(66.6)$ \\
\hline & Postmenopausal & $10(47.6)$ & $8(33.3)$ \\
\hline
\end{tabular}

Abbreviation: ER: esterogene receptor, PR: progesterone receptor.

RNA, $5 \mathrm{pmol} / \mu \mathrm{l}$ of each stem-loop primers $(0.5 \mu \mathrm{l}), 2$ $\mu \mathrm{l}$ of 5 X buffer (Yekta Tajhiz Azma ${ }^{\circledR}$, Iran), $1 \mu \mathrm{l}$ of each dNTP (Metabion, Germany), $0.5 \mu$ l of RNase inhibitor (Metabion, Germany), and 100U (0.5 $\mu \mathrm{l})$ of MMLVR (Yekta Tajhiz Azma ${ }^{\circledR}$, Iran). RNA was reverse transcribed to cDNA with the following conditions: the mixture was incubated for $30 \mathrm{~min}$ at $16{ }^{\circ} \mathrm{C}$, at $42{ }^{\circ} \mathrm{C}$ for $30 \mathrm{~min}$, and at $72{ }^{\circ} \mathrm{C}$ for $10 \mathrm{~min}$. Synthesis of cDNA was done using a peqSTAR $2 X$ Gradient Thermocycler (PEQLAB Biotechnologies GMBH, Erlangen, Germany).

\subsection{Quantitative real-time polymerase chain} reaction ( $q R T-P C R)$

Real-time PCR was done by SYBR Premix Ex TaqTM II (Takara, Japan) to analyze the microRNA-
miR-26a

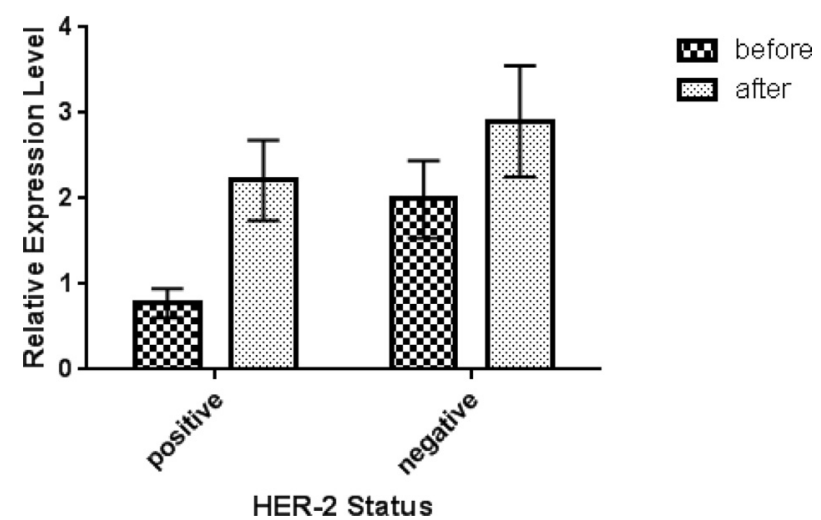

Fig 2. Relative expression of serum miR-26a-5p in HER-2 negative and positive breast cancer patients before and after treatment. 
Table 3. Comparison of serum level of miR-26a-5p based on menopausal status and age category in HER-2 positive patient before and after treatment.

\begin{tabular}{lllll}
\hline Variable & & Groups & & \\
\cline { 3 - 5 } & & $\begin{array}{l}\text { Before HER-2 positive } \\
\text { Mean } \pm \text { SE (Median) }\end{array}$ & $\begin{array}{l}\text { After HER-2 positive } \\
\text { Mean } \pm \text { SE (Median) }\end{array}$ & p. value \\
\hline Menopausal status & Premenopausal & $0.603 \pm 0.197(0.248)$ & $1.971 \pm 0.527(0.986)$ & 0.031 \\
& Postmenopausal & $1.145 \pm 0.312(1.212)$ & $2.706 \pm 0.987(1.452)$ & 0.263 \\
Age status & $\leq 48$ & $0.643 \pm 0.189(0.255)$ & $1.921 \pm 0.498(1.118)$ & 0.039 \\
& $48<$ & $1.127 \pm 0.359(1.148)$ & $2.933 \pm 1.1091(1.469)$ & 0.237 \\
\hline
\end{tabular}

Table 4. Characteristics of breast cancer patients and the relationship between serum levels of miR-26a-5p and clinicopathological parameters of HER-2 positive breast cancer patients.

\begin{tabular}{llll}
\hline Variable & & Groups & \\
\cline { 2 - 4 } & & $\begin{array}{l}\text { Before HER-2 positive } \\
\text { Mean } \pm \text { SE (Median) }\end{array}$ & After HER-2 positive \\
Mean \pm SE (Median)
\end{tabular}

26a expression as a target gene and microRNA016 was used as endogenous control, implemented in the real-time PCR cycler RotorGene Q (QIAGEN $\mathrm{GmbH}$, Hilden, Germany). Briefly, The qRT-PCR was perfomed in a volume of $20 \mu$ containing: A 20 $\mu 1$ real-time PCR reaction mixture consisted of $1 \mu 1$ cDNA, $10 \mu \mathrm{l}$ Maxima SYBR-Green/ROX qPCR Master Mix 2X (Ampliqon, Bie \& Berntsen, Herlev, Denmark), and $5 \mathrm{pmol} / \mu \mathrm{l}$ of each primer (Table 1 ). For amplification of the target miRNAs, the PCR cycling conditions were as follows: 15 minutes at 95 ${ }^{\circ} \mathrm{C}$, followed by 40 cycles of $12 \mathrm{~s}$ at $95{ }^{\circ} \mathrm{C}$, and $25 \mathrm{~s}$ at $60{ }^{\circ} \mathrm{C}$. The expression level of microRNA-26a-5p was normalized to microRNA-16 by the relative expression software tool.

\subsection{Statistical analysis}

In this study, we used the Shapiro-Wilk test for determining normal distribution of expression microRNA-26a-5p level. In addition, Wilcoxon test was perfomed for comparing the paired serum samples before and after treatment in HER $-2^{+}$and HER-2- BC patients. Besides, we performed Wilcoxon test to evaluate the effect of clinicopathological characteristics before and after treatment in HER-2 positive patients.

\section{Results}

A total of 45 (24 HER-2 ${ }^{+}$and 21 HER-2 ${ }^{-}$) patients participated for determining the expression microRNA-26a-5p status before and after Docetaxel therapy in HER-2 $2^{-}$group and Docetaxel/Trastuzumab therapy in HER-2 $2^{+}$group. All the clinicopathological features of the $45 \mathrm{BC}$ patients are shown in Table 2 . In addition, age in HER-2 ${ }^{+}$patients was not

\section{miR-26a}

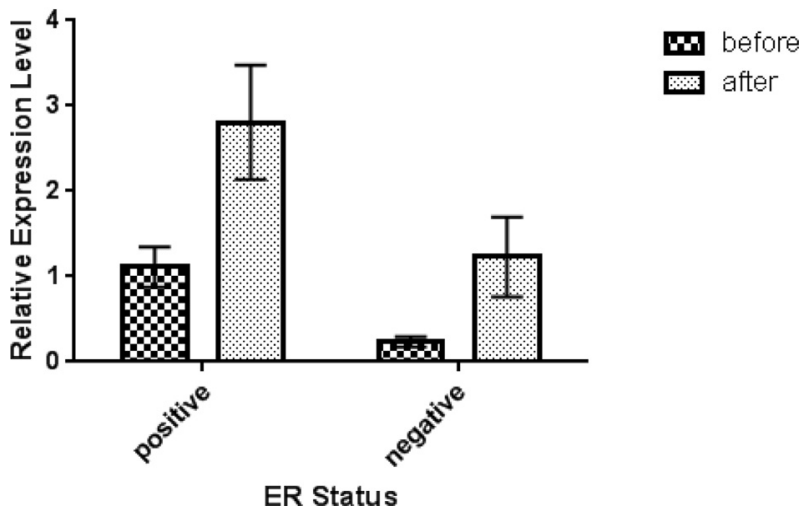

Fig 3. Relative expression of serum miR-26a-5p in HER-2 positive/ER Positive and HER-2 positive/ER Negative breast cancer patients before and after treatment. Abbreviation: ER: esterogene receptor. 
miR-26a

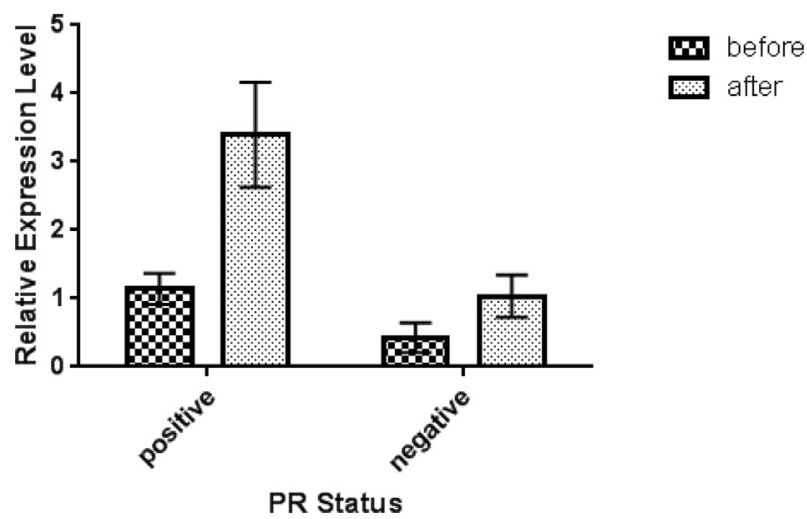

Fig 4. Relative expression of serum miR-26a-5p in HER-2 positive/PR Positive and HER-2 positive/PR Negative breast cancer patients before and after treatment. Abbreviation: PR: progesterone receptor.

significantly different from the HER-2 ${ }^{-}$patients $\left(\right.$ HER $^{+}{ }^{+}$and HER-2 ${ }^{-}$: Mean \pm SD $(49.9 \pm 10.1),(51.1$ $\pm 11.2)$, respectively).

\subsection{Comparison of serum expression microRNA-} 26a-5p levels in HER-2 ${ }^{+}$and HER-2- BC patients

The serum expression microRNA -26a-5p levels in HER-2 patients after treatment with Docetaxel increased in crude data as compared with its expression levels before treatment (not significant, p.value $=0.141$ ). In HER-2 ${ }^{+}$patients, the expression microRNA-26a-5p status significantly increased after treatment with Docetaxel/Trastuzumab in comparison with before treatment (p.value $=0.012$ ) (Fig. 2). In addition, were not any observed significant differences in expression microRNA-26a-5p levels before treatment with Docetaxel in both groups (HER-2 positive and HER-2') (p.value > 0.05). Moreover, we observed a significant difference in expression of microRNA-26a-5p in HER-2and HER-2 ${ }^{+}$patients after treatment (p.value < 0.05).

To evaluate the effect of menopausal status on the expression microRNA-26a-5p levels, patients were divided into two groups: premenopausal and postmenopausal. The expression microRNA-26a-5p status was significantly increased in HER-2 ${ }^{+}$premenopausal women after treatment with Docetaxel/ Trastuzumab when compared to before treatment (p.value $=0.031$ ). However, in postmenopausal women, there was no significant difference in microRNA-26a-5p expression levels before and after treatment with Docetaxel/Trastuzumab in HER-2 ${ }^{+}$ patients (p.value $=0.263$ ). In addition, to assess the impact of ageing on the serum expression levels of
microRNA-26a-5p, all of the HER-2 ${ }^{+}$patients were categorized into two groups, i.e. $\geq 48$ years and $>48$ years. The results showed that in HER $-2^{+}$patients, expression microRNA-26a-5p levels were significantly higher in patients $\geq 48$ years after treatment with Docetaxel/Trastuzumab compared to before treatment (p.value $=0.039$ ), whereas in $>48$ years HER-2 ${ }^{+}$patients, there was no significantly difference before and after treatment with the mentioned drugs (p.value $=0.273)($ Table 3$)$.

\subsection{Relationship between expression microRNA- 26a-5p levels and clinicopathological features before and after in HER-2 ${ }^{+}$patients}

In Table 4, clinicopathological features of HER-2 ${ }^{+}$ $\mathrm{BC}$ patients are shown. As can be seen, there is a significant relationship between expression microRNA-26a-5p levels and tumor size (pT3) before and after treatment with Docetaxel/Trastuzumab (p.value $=0.043$ ). Besides, according to histological staging, we observed that there was a significant difference between serum microRNA-26a-5p levels with stage III, before and after treatment in HER-2 positive group (p.value $=0.042$ ). Furthermore, according to the status of ER and PR, expression levels of microRNA-26a-5p had a significant association with ER negative and PR positive before and after treatment in HER-2 ${ }^{+}$individuals (p.value $=0.049$ and 0.034, respectively) (Figs. 3 and 4, respectively).

\section{Discussion}

$\mathrm{BC}$ is the most prevalent noncoutaneous malignancy among women $[25,26]$. Based on its etiology, both genetic and environmental factors have a crucial role in the incidence of this malignancy $[27,28]$. One of the most important genetic factors are MiRNAs, as multifunctional ncRNAs, that have an important function in the consistency and translational efficacy of target RNAs [29-31].

Our data have revealed the upregulation of microRNA-26a in patients with HER-2+ BC, who were treated with trastuzumab. Based on previous studies, the microRNA-26a as a tumor suppressormiR has been reduced in all BC cell lines, and in clinical specimens. Moreover, the expression of microRNA-26a is significantly correlated with the HER-2 status of patients with BC $[29,24]$. As mentioned, this upregulation occurs in trastuzumab sensitive cell lines but not in acquired or innately resistant trastuzumab cell lines such as BT474r and HCC1954 [32]. Interestingly, upregulation of microRNA-26a was not seen in HER-2- BC patients in our study and these results are consistent with 


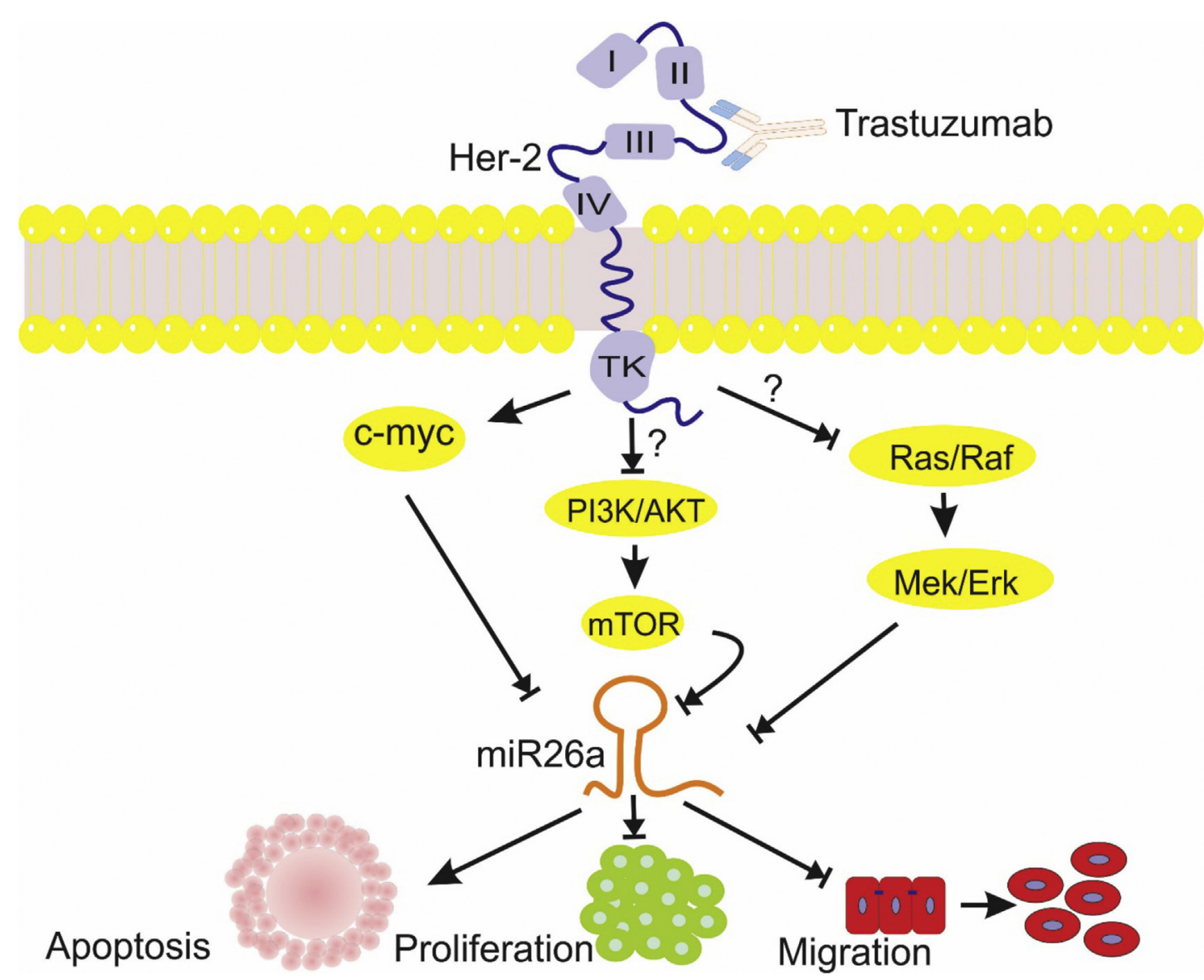

Fig 5. The schematic representation of the effects of trastuzumab on the HER-2 receptor in breast cancer cells. This schematic representation shows the effect of trastuzumab on the HER-2 receptor in breast cancer. Based on our knowledge, the miR-26a inhibits cancer proliferation, migration, and is able to induce apoptosis. Multiple signaling pathways, such C-MYC, PI3K/AKT, and RAS/RAF can repress the expression levels of miR-26a. However, in the HER-2 + BC patients, trastuzumab therapy reduces the levels of these signaling pathways, and thus, increases the miR-26a levels. (The question mark means that the exact mechanism of action is still unknown).

other studies that showed the downregulation of microRNA-26a in triple-negative BC (TNBC) [33]. Recently, growing evidence has revealed that microRNA-26a inhibits cancer proliferation and migration, and is able to induce cell apoptosis. Reduction in the microRNA-26a expression may be due to the numerous regulatory events, such as $\mathrm{LOH}$ at chromosome $3 \mathrm{p} 22$, mutation in p53 that enhances the post-transcriptional maturation of microRNA-26a, and downregulation of DICER that play a central role in the miRNAs maturation [3436]. It is not clear how trastuzumab can upregulate the microRNA-26a expression, but a number of mechanisms may explain this regulation (Fig. 5). One possible mechanism is its regulation by MYC. As we know, C-MYC is able to bind transcriptional start sites of the microRNA-26a and repress the expression of this miRNA. MYC is located in the downstream of the HER-2 signaling pathway. Thereby, trastuzumab therapy of HER-2 + BC patients reduces the MYC levels and subsequently increases the microRNA-26a level [37,38]. Besides, trastuzumab inhibits growth factor signaling cascades (including PI3K/AKT/mTOR and RAS/RAF/ MEK/MAK kinase) in the downstream pathway of HER-2 by dimerization of HER2. It seems that reducing of the expression levels of these oncogenic factors can lead to an increase in the microRNA-26a, but a confirmation of this hypothesis needs additional studies $[39,40]$.

Taken together, we introduced microRNA-26a, in form of tumor suppressive miRNA in BC based on the clinico-pathological variables, assessed in the present study. In addition, the serum expression of microRNA-26a increased in patients who were in pT3 (TNM staging system) after trastuzumab therapy, and these results are consistent with other studies in which microRNA-26a was upregulated in non-TNBC compared with TNBC cases [33]. Upregulation of miR-26a in BC patients with T3-T4 has been much higher, compared to those with T1-T2 [33]. By contrast, it was reported that miR-26a were 
overexpressed 3 times and 1.5 times correspondingly in TNBC relative to non-TNBC tumors [41]. Moreover, we observed that expression the microRNA-26a levels were correlated with the tumor stage and this microRNA was overexpressed in stage III of HER-2+ BC patients after trastuzumab therapy. In addition, our results have revealed that HER-2+ BC patients with primary tumors had low expression microRNA-26a levels compared to the advanced stages, and this is consistent with previous published study [42]. For instance, it has been shown that miR-26a has different expressions in various stages of gastric cancer: in stage I/II the expression of microRNA-26a was 37\% and in stage III/IV this rate increased to $77 \%$ [43]. We have not observed any correlation between the expression of microRNA-26a and lymph node metastasis, and it seems that the microRNA-26a probably cannot play a key role in the inhibition of lymph node metastasis. Studies have shown that there are multiple genes as potential downstream target genes of microRNA-26a, which have important functions in tumor growth and metastasis. These include Prime time entertainment network (PTEN), metadherin $(\mathrm{MTDH})$, cell division protein kinase 6 (CDK6), enhancer of zeste homolog 2 (EZH2), myeloid cell leukemia 1 (MCL-1), Pyruvate Dehydrogenase Complex Component X (PDHX), Chromodomain-helicase-DNAbinding protein 1(CHD1), Growth regulation by estrogen in breast cancer 1 (GREB1), and Karyopherin Alpha 2 (KPNA2) [33,44]. MTDH overexpression, for instance, is associated with the invasion and metastasis in BC, and it has been suggested that the molecular mechanism of this metastasis is related to the induction of the epithelial mesenchymal transition (EMT) in BC and microRNA-26a can inhibit the mRNA and protein levels of MTDH [33,45].

Consequently, we provided evidence that microRNA-26a increases in ER-/HER-2+ compared with ER+/HER-2 + BC after trastuzumab therapy. According to other studies on $\mathrm{ER}+\mathrm{BC}$, with tamoxifen resistance, the reduced level of microRNA-26a has been responsible for this resistance in ER + patients [46]. In addition, our work showed that the microRNA-26a is upregulated in PR +/HER-2+ patients, compared with PR-/HER-2+ patients, after treatment with trastuzumab. This upregulation can be independently due to the effect of trastuzumab, but it is the microRNA-26a that regulates the encoding gene of progesterone receptor (PR) [47].

In our study, we have observed an increase in the microRNA-26a expression levels, among premenopausal and $\leq 48$ years old HER- $2+$ BC patients, after trastuzumab therapy. According to the published studies, HER-2 expression is associated with clinicopathological features, like menopausal status [48,33]. As we know, serum concentration of estrogen is generally evaluated in premenopausal women, compared with postmenopausal ones. In addition, estrogen can induce expression of some growth factors, encoding genes related to various receptors, such as HER-2 [49]. Consequently, expression levels microRNA-26a in premenopausal HER-2+ BC patients are induced after the treatment with trastuzumab.

This study has important strengths that include: 1) providing evidence demonstrating that the miR-26a levels (measured in clinical specimens) are susceptible to modulation by trastuzumab, 2) presenting initial results of the miR-26a analysis, and comparing it with the follow-up findings, in patients with HER-2+ BC and HER-2 - BC. However, further large-scale studies are required to confirm our hypothesis. Limitations of our study include a small sample size, short time period of the study followup, difficulties to access clinical data of the patients, and loss of communication with some patients during the follow-up.

Overall, future research with regard to potential predictive biomarkers for trastuzumab targeted therapy effects is needed, in patients with HER-2 + BC. Hopefully, in the future, the miR-26a assessment would help the medical-oncology teams more accurately predict, which patients may have the best chance to positively respond to the treatment with trastuzumab.

\section{Conclusion}

Trastuzumab therapy increases the expression of microRNA-26a in HER-2+ BC patients. Hence, evaluating microRNA-26a levels during the trastuzumab therapy could be considered as a useful biomarker for monitoring the response to treatment in patients with HER-2+ BC. However, further studies on large populations of women with HER$2+\mathrm{BC}$ are needed to explore this possible novel biomarker, in more detail, within various clinical contexts.

\section{Acknowledgments}

We would like to thank Dr. Mahmood Maniati for proofreading and language editing of the earlier drafts of this manuscript, and Dr. Ghasem Janbabaei for assistance in this study. 


\section{Abbreviations}

\begin{tabular}{|c|c|}
\hline $\begin{array}{l}\mathrm{BC} \\
\mathrm{miR}-26 \mathrm{a}\end{array}$ & $\begin{array}{l}\text { Breast cancer } \\
\text { microRNA-26a-5p }\end{array}$ \\
\hline HER-2 & human epidermal growth factor receptor 2 \\
\hline EGFR & epidermal growth factor receptor \\
\hline ADCC & antibody-dependent cell-mediated cytotoxicity \\
\hline MTDH & metadherin \\
\hline EZH2 & enhancer of zeste homolog 2 \\
\hline MCL-1 & myeloid cell leukemia 1 \\
\hline CCNE2 & cyclin E2 \\
\hline FISH & fluorescence in situ hybridization \\
\hline IHC & immunohistochemical \\
\hline TNBC & triple-negative $\mathrm{BC}$ \\
\hline PTEN & Prime time entertainment network \\
\hline PDHX & Pyruvate Dehydrogenase Complex Component $\mathrm{X}$ \\
\hline CHD1 & Chromodomain-helicase-DNA-binding protein 1 \\
\hline GREB1 & Growth regulation by estrogen in breast cancer 1 \\
\hline KPNA2 & Karyopherin Alpha 2 \\
\hline $\mathrm{LOH}$ & loss of heterozygosity \\
\hline EMT & epithelial-mesenchymal transition \\
\hline
\end{tabular}

\section{Availability of data and materials}

The datasets applied and/or analyzed in the current research are available from the corresponding author on reasonable request.

\section{Author contributions statement}

Hadi Parsian: Supervised the data and critically revised the data.

Sadra Samavarchi Tehrani: Prepared the writing and drafting.

Ehsan Zaboli: Sampled blood, Collected the data.

Farzin Sadeghi: Sampled blood, statistically analyzed.

Soraya Khafri: Statistically analyzed, prepared the figures.

Mahnoosh Rafie: Collected the data, Collected the data.

Ansar Karimian: Prepared the figures and tables, Editing.

\section{Ethics approval and informed consent}

This study was funded by the research deputy of Babol University of Medical Sciences (grant number: 3875), our study was accepted by the Ethics Committee of our institute and for all individuals (1396.65).

\section{Conflicts of interest}

None.

\section{References}

[1] Bray F, Ferlay J, Soerjomataram I, Siegel RL, Torre LA, Jemal A. Global cancer statistics 2018: GLOBOCAN estimates of incidence and mortality worldwide for 36 cancers in 185 countries. Canc J Clin 2018 Nov;68(6):394-424.

[2] Gong C, Yao Y, Wang Y, Liu B, Wu W, Chen J, Su F, Yao H, Song E. Up-regulation of miR-21 mediates resistance to trastuzumab therapy for breast cancer. J Bio Chem 2011; 286(21):19127-37.

[3] Nguyen PL, Taghian AG, Katz MS, Niemierko A, Abi Raad RF, Boon WL, Bellon JR, Wong JS, Smith BL, Harris JR. Breast cancer subtype approximated by estrogen receptor, progesterone receptor, and HER-2 is associated with local and distant recurrence after breast-conserving therapy. J Clin Oncol 2008;26(14):2373-8.

[4] Abramson V, Arteaga CL. New strategies in HER2-overexpressing breast cancer: many combinations of targeted drugs available. In: Clinical Cancer Research:clincanres. 1947. 2010; 2011.

[5] Samavarchi Tehrani S, Gharibi S, Movahedpour A, Goodarzi G, Jamali Z, Khatami SH, Maniati M, Ranjbar M, Shabaninejad Z, Savardashtaki A. Design and evaluation of scFvRTX-A as a novel immunotoxin for breast cancer treatment: an in silico approach. J Immuno Immunochem 2020:1-15.

[6] Rimawi MF, Schiff R, Osborne CK. Targeting HER2 for the treatment of breast cancer. Ann Rev Med 2015;66:111-28.

[7] Hudis CA. Trastuzumab-mechanism of action and use in clinical practice. New Engl J Med 2007;357(1):39-51.

[8] Marty M, Cognetti F, Maraninchi D, Snyder R, Mauriac L, Tubiana-Hulin M, Chan S, Grimes D, Antón A, Lluch A. Randomized phase II trial of the efficacy and safety of trastuzumab combined with docetaxel in patients with human epidermal growth factor receptor 2-positive metastatic breast cancer administered as first-line treatment: the M77001 study group. J Clinical Oncol 2005;23(19):4265-74.

[9] Nishimura R, Okumura Y, Arima N. Trastuzumab monotherapy versus combination therapy for treating recurrent breast cancer: time to progression and survival. Breast Canc 2008;15(1):57-64.

[10] Brufsky A. Trastuzumab-based therapy for patients with HER2-positive breast cancer: from early scientific development to foundation of care. Am J Clin Oncol 2010;33(2): 186-95.

[11] Halimi M, Shahabi A, Moslemi D, Parsian H, Asghari SM, Sariri R, Yeganeh F, Zabihi E. Human serum miR-34a as an indicator of exposure to ionizing radiation. Radiat Environ Biophy 2016;55(4):423-9.

[12] Halimi M, Parsian H, Asghari SM, Sariri R, Moslemi D, Yeganeh F, Zabihi E. Clinical translation of human microRNA 21 as a potential biomarker for exposure to ionizing radiation. Transl Res 2014;163(6):578-84.

[13] Tehrani SS, Karimian A, Parsian H, Majidinia M, Yousefi B. Multiple functions of long non-coding RNAs in oxidative stress, DNA damage response and cancer progression. J Cell Biochem 2018;119(1):223-36.

[14] Weber JA, Baxter DH, Zhang S, Huang DY, Huang KH, Lee MJ, Galas DJ, Wang K. The microRNA spectrum in 12 body fluids. Clin Chem 2010;56(11):1733-41.

[15] Wang W, Zhang Y, Zhu B, Duan T, Xu Q, Wang R, Lu L, Jiao Z. Plasma microRNA expression profiles in Chinese patients with rheumatoid arthritis. Oncotarget 2015;6(40):42557.

[16] Maniati MS, Maniati M, Yousefi T, Ahmadi-Ahangar A, Tehrani SS. New insights into the role of microRNAs and long noncoding RNAs in most common neurodegenerative diseases. J Cell Biochem 2019 Jun;120(6):8908-18.

[17] Ranjbar R, Karimian A, Aghaie Fard A, Tourani M, Majidinia M, Jadidi-Niaragh F, Yousefi B. The importance of miRNAs and epigenetics in acute lymphoblastic leukemia prognosis. J Cell Physiol 2019;234(4):3216-30. 
[18] Heydari N, Nikbakhsh N, Sadeghi F, Farnoush N, Khafri S, Bastami M, Parsian H. Overexpression of serum MicroRNA$140-3 p$ in premenopausal women with newly diagnosed breast cancer. Gene 2018;655:25-9.

[19] Ma T, Yang L, Zhang J. MiRNA5423p downregulation promotes trastuzumab resistance in breast cancer cells via AKT activation. Oncol Rep 2015;33(3):1215-20. https://doi.org/ 10.3892/or.2015.3713.

[20] Wuerkenbieke D, Wang J, Li Y, Ma C. miRNA-150 downregulation promotes pertuzumab resistance in ovarian cancer cells via AKT activation. Arc Gynecol Obst 2015;292(5): 1109-16. https://doi.org/10.1007/s00404-015-3742-x.

[21] Le X-F, Almeida MI, Mao W, Spizzo R, Rossi S, Nicoloso MS, Zhang S, Wu Y, Calin GA, Bast Jr RC. Modulation of MicroRNA-194 and cell migration by HER2-targeting trastuzumab in breast cancer. PloS one 2012;7(7):e41170.

[22] Gao J, Li L, Wu M, Liu M, Xie X, Guo J, Tang H, Xie X. MiR26a inhibits proliferation and migration of breast cancer through repression of MCL-1. PloS one 2013;8(6):e65138.

[23] Zhang B, Liu X-X, He J-R, Zhou C-X, Guo M, He M, Li M-F, Chen G-Q, Zhao Q. Pathologically decreased miR-26a antagonizes apoptosis and facilitates carcinogenesis by targeting MTDH and EZH2 in breast cancer. Carcinogenesis 2010; 32(1):2-9.

[24] Ichikawa T, Sato F, Terasawa K, Tsuchiya S, Toi M, Tsujimoto G, Shimizu K. Trastuzumab produces therapeutic actions by upregulating miR-26a and miR-30b in breast cancer cells. PloS one 2012;7(2):e31422.

[25] Runowicz CD, Leach CR, Henry NL, Henry KS, Mackey HT, Cowens-Alvarado RL, Cannady RS, Pratt-Chapman ML, Edge SB, Jacobs LA, Hurria A, Marks LB, LaMonte SI, Warner E, Lyman GH, Ganz PA. Am Canc Soc 2016;66(1): 43-73. https://doi.org/10.3322/caac.21319.

[26] Colditz GA, Bohlke K. Priorities for the primary prevention of breast cancer64; 2014. p. 186-94. https://doi.org/10.3322/ caac. 21225 (3).

[27] Siegel RL, Miller KD, Jemal A. Cancer statistics, 201868; 2018. p. 7-30. https://doi.org/10.3322/caac.21442 (1).

[28] Abolghasemi M, Tehrani SS, Yousefi T, Karimian A, Mahmoodpoor A, Ghamari A, Jadidi-Niaragh F, Yousefi M, Kafil HS, Bastami M. Critical roles of long noncoding RNAs in breast cancer. J Cell Physiol 2020;235(6):5059-71.

[29] Gao J, Li L, Wu M, Liu M, Xie X, Guo J, Tang H, Xie XJPo. MiR-26a inhibits proliferation and migration of breast cancer through repression of MCL-18; 2013, e65138 (6).

[30] Mirhosseini SA, Sarfi M, Samavarchi Tehrani S, Mirazakhani M, Maniati M, Amani J. Modulation of cancer cell signaling by long noncoding RNAs. J Cell Biochem 2019;120(8): 12224-46.

[31] Abolghasemi M, Tehrani SS, Yousefi T, Karimian A, Mahmoodpoor A, Ghamari A, Jadidi-Niaragh F, Yousefi M, Kafil HS, Bastami M. MicroRNAs in breast cancer: Roles, functions, and mechanism of actions. J Cell Physiol 2020;235(6): 5008-29.

[32] Tormo E, Adam-Artigues A, Ballester S, Pineda B, Zazo S, González-Alonso P, Albanell J, Rovira A, Rojo F, AJSr Lluch. The role of miR-26a and miR-30b in HER2+ breast cancer trastuzumab resistance and regulation of the CCNE2 gene7; 2017. p. 41309.

[33] Liu P, Tang H, Chen B, He Z, Deng M, Wu M, Liu X, Yang L, Ye F, Xie X. miR-26a suppresses tumour proliferation and metastasis by targeting metadherin in triple negative breast cancer. Canc Lett 2015;357(1):384-92.

[34] Grelier G, Voirin N, Ay A, Cox D, Chabaud S, Treilleux I, Leon-Goddard S, Rimokh R, Mikaelian I, CJBjoc Venoux. Prognostic value of Dicer expression in human breast cancers and association with the mesenchymal phenotype101; 2009. p. 673 (4)

[35] Suzuki HI, Yamagata K, Sugimoto K, Iwamoto T, Kato S, Miyazono KJN. Modulation of microRNA processing by p53460; 2009. p. 529 (7254).

[36] Chen L-C, Matsumura K, Deng G, Kurisu W, Ljung B-M, Lerman MI, Waldman FM, Smith HSJCr. Deletion of two separate regions on chromosome $3 p$ in breast cancers 54 1994. p. 3021-4 (11).

[37] Le X-F, Pruefer F, RCJCc Bast. HER2-targeting antibodies modulate the cyclin-dependent kinase inhibitor p27Kip1 via multiple signaling pathways4; 2005. p. 87-95 (1).

[38] Sander S, Bullinger L, Klapproth K, Fiedler K, Kestler HA, Barth TF, Möller P, Stilgenbauer S, Pollack JR, Wirth TJB. MYC stimulates EZH2 expression by repression of its negative regulator miR-26a112; 2008. p. 4202-12 (10).

[39] Nahta R, Esteva FJ. HER2 therapy: molecular mechanisms of trastuzumab resistance8; 2006. p. 215 (6)

[40] Okutur K, Bassulu N, Dalar L, Aydin K, Bozkurt M, Pilanci KN, Dogusoy GB, Tecimer C, Mandel NM, Demir G. Predictive and prognostic significance of p27, Akt, PTEN and PI3K expression in HER2-positive metastatic breast cancer. Asian Pac J Canc Prev 2015;16(7):2645-51.

[41] M'hamed IF, Privat M, Trimeche M, Penault-Llorca F, Bignon Y-J, Kenani A. miR-10b, miR-26a, miR-146a And miR-153 expression in triple negative vs non triple negative breast cancer: potential biomarkers. Pathol Oncol Res 2017; 23(4):815-27.

[42] Jansen M, Reijm E, Sieuwerts A, Ruigrok-Ritstier K, Look M, Rodriguez-Gonzalez F, Heine A, Martens J, Sleijfer S, Foekens J. High miR-26a and low CDC2 levels associate with decreased EZH2 expression and with favorable outcome on tamoxifen in metastatic breast cancer. Breast Can Res Treat 2012;133(3):937-47.

[43] Wu P, Zuo X, Deng H, Liu X, Liu L, Ji A. Roles of long noncoding RNAs in brain development, functional diversification and neurodegenerative diseases. Brain Res Bull 2013, 97:69-80.

[44] Huse JT, Brennan C, Hambardzumyan D, Wee B, Pena J, Rouhanifard SH, Sohn-Lee C, le Sage C, Agami R, Tuschl TJG, development. The PTEN-regulating microRNA miR$26 a$ is amplified in high-grade glioma and facilitates gliomagenesis in vivo23; 2009. p. 1327-37 (11).

[45] Li X, Kong X, Huo Q, Guo H, Yan S, Yuan C, Moran MS, Shao C, Yang QJCs. Metadherin enhances the invasiveness of breast cancer cells by inducing epithelial to mesenchymal transition102; 2011. p. 1151-7 (6).

[46] Tan S, Ding K, Chong Q-Y, Zhao J, Liu Y, Shao Y, Zhang Y, Yu Q, Xiong Z, Zhang WJ. Post-transcriptional regulation of ERBB2 by $\mathrm{miR} 26 \mathrm{a} / \mathrm{b}$ and HuR confers resistance to tamoxifen in estrogen receptor-positive breast cancer cells. JoBC 2017; 292(33):13551-64.

[47] Maillot G, Lacroix-Triki M, Pierredon S, Gratadou L, Schmidt S, Bénès $\mathrm{V}$, Roché $\mathrm{H}$, Dalenc F, Auboeuf D, SJCr Millevoi. Widespread estrogen-dependent repression of micrornas involved in breast tumor cell growth69; 2009. p. 8332-40 (21).

[48] Traina A, Agostara B, Marasa L, CalabrÒ M, Zarcone M, GJAotNYAoS Carruba. HER2/neu expression in relation to clinicopathologic features of breast cancer patients1089; 2006. p. 159-67 (1)

[49] Wakeling AE, Osborne CK, Weiss H, Shou J, Schiff R, Ali S, Massarweh S. Mechanisms of Tamoxifen Resistance: Increased Estrogen Receptor-HER2/neu Cross-Talk in ER/ HER2-Positive Breast Cancer. J Nation Canc Inst 2004 96(12):926-35. https://doi.org/10.1093/jnci/djh166\%J. JNCI: Journal of the National Cancer Institute. 